\title{
ROLE OF CAD/CAM IN DESIGNING, DEVELOPING AND MANUFACTURING OF NEW PRODUCTS
}

\author{
Pawan Sharma $^{1}$, Khagendra Pathak ${ }^{2}$, B. K. Sharma ${ }^{3}$ \\ ${ }^{1}$ Department of Mechanical Engineering, VIT (East), Jaipur, India \\ ${ }^{2}$ Department of Mechanical Engineering, MAIET, Jaipur, India \\ ${ }^{3}$ Department of Mechanical Engineering, VIT (East), Jaipur, India
}

\begin{abstract}
Smart CAD/CAM technologies for superior product modeling in the intelligence of designing complete product variants become more and more pertinent in future. Many design techniques to help interdisciplinary design actions in different engineering domains in addition to consequent processes have to be developed. A necessary job to achieve this aim is to permanently investigate the present state of the art, emerging trends, new approaches, in addition to industrial problems and requirements about the entire CAD/CAM area. With the aim of direct future research and development activities as close as possible to the continuously rising requirements of a worldwide market we carried out a wide-ranging national study in cooperation with one of the Germans leading CAD/CAM magazines.

In this way, it became possible to reach a representative amount of users, to obtain their experience based assessments on today's most important aspects of CAD/CAM technology. The results of this examination are summarized in this paper to give system developers, engineers, and researchers an overview of the present condition as well as to serve as a direction for decision makers in the Design and Development areas.
\end{abstract}

Keywords: CAD/CAM; CIM; CAPP; Product development; Design and Manufacture.

\section{INTRODUCTION}

In a globally competitive environment, time compression strategies in product development are of critically importance. Certain products have long development cycle times. Examples are aircraft and automobiles. In some of the products like computers, technological obsolescence puts a constraint on the product development time.

As soon as a new microprocessor is released in the market, the manufacturers of the computers via with each other to market computers based on the new processor. Frequent releases of newer and newer microprocessors have consistently narrowed down the product life cycle of computers.

The pursuit of excellence in performance has resulted in new technologies being developed in entertainment electronics. The life cycle of entertainment electronic products is thus reduced, thereby necessitating new products being delivered to the market at reduced intervals.

The time compression in product development has also necessitated:

- Avoidance of design errors, rework of components and tooling,

- Better data management,

- Improved supply chain management,

- Attaining higher and higher levels of performance,
- $\quad$ Providing quality levels superior to what is offered by competitors,

- Above all supplying the product at the lowest possible cost.

\section{STAGES IN PRODUCT DEVELOPMENT}

The need to be right first time every time has changed the approach to design. The initial phase of design consists of conceptual design, design analysis and performance simulation. The phase is highly iterative as shown in fig. 1 .

The techniques like concurrent engineering, failure mode and effect analysis etc., are used to ensure a reliable and quality design at this stage. This is followed by detailed design, tool design, prototype manufacture and evaluation and documentation. (Fig. 2)

The next phase of product development involved second phase of engineering where the design may be further refined. Here focus is on manufacturing planning, data management, supply chain management and manufacture. 


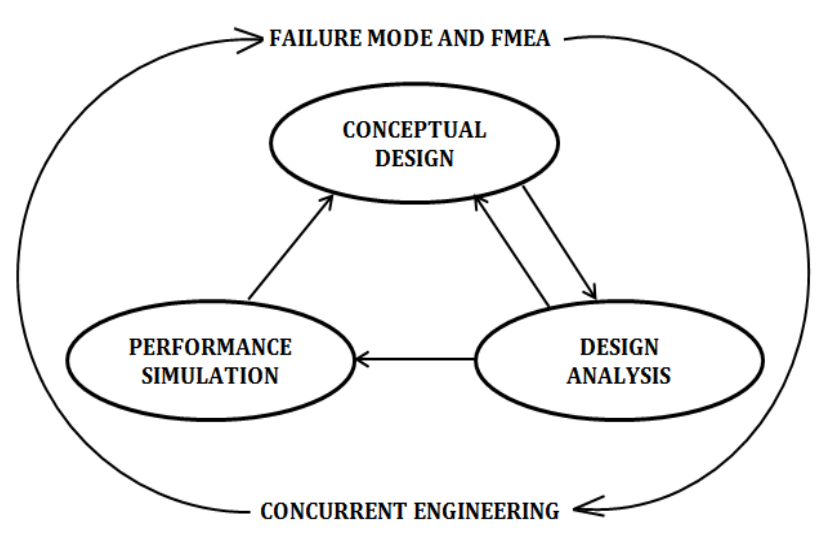

Fig. 1: Product Development Scenario

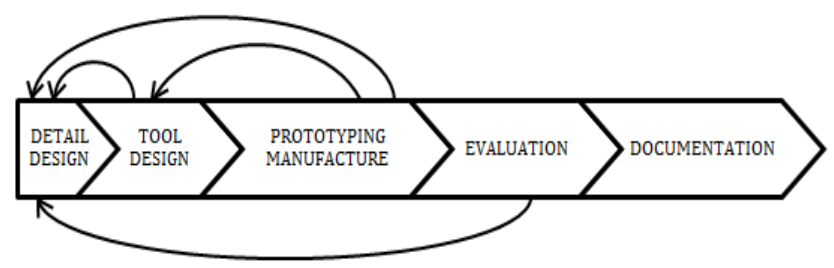

Fig. 2: Prototyping Stage of Product Development

\section{PRODUCT DEVELOPMENT AND}

\section{MANUFACTURE}

CAD/CAM as an enabling technology for product development and manufacture Developments in computers and software relating to $\mathrm{CAD} / \mathrm{CAM}$ have made $\mathrm{CAD} / \mathrm{CAM}$ an indispensable enabling technology for time compression in product development. This is made possible by an integrated approach to carry out different activities in product development through seamless data transfer. (Fig. 3) CAD/CAM technologies help to simulate and the manufacturing methodologies in the following ways:

\subsection{Assemble Analysis}

With the help of today's CAD/CAM technology, design team can work in a top down and bottom up manner to create a complete electronic product mock up. Once an assembly is completed, solids based kinematic analysis can be used to simulate complex motions of mechanisms as well to carry out tolerance analysis.

\section{2 $\mathrm{CAD} / \mathrm{CAM}$ in Aid to Manufacture through}

\section{Better Tool Design and Optimize Manufacturing}

\section{Processes}

Manufacturing simulation uses a set of powerful CAD/Cam tools which seek to create virtual manufacturing environment. Many uncertainties which may result in time delay, rework or production of defective parts can be eliminated through simulation or manufacturing, whether it is CNC machining, plastic injection moulding, casting, forging or welding.

\subsection{Rapid Prototyping}

Rapid Prototyping technology is being more widely employed to verify and improve designs, rapid tooling as well as initial prototypes.

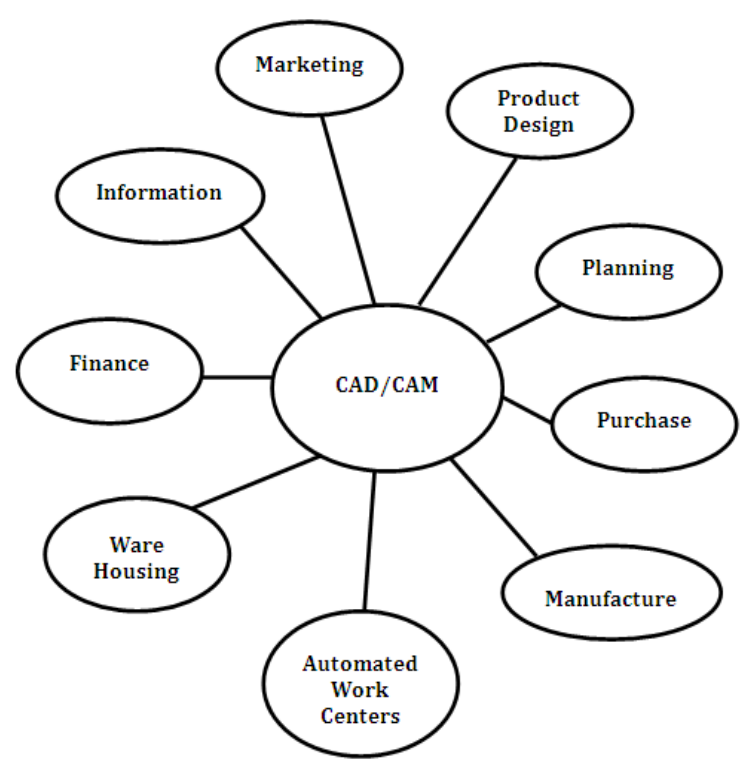

Fig. 3: CAD/CAM Database

\subsection{Agile Manufacturing}

Agile Manufacturing is oriented in the direction of high mix/ low volume, flexibility and adding velocity in the production process. It applies to environments somewhere configurable, customized, or dedicated orders, suggest a competitive improvement. Consequently, that manufacturing has been one of most important strategies of new enterprises. In the atmosphere of the market ongoing to vary the quality, speed, quick responds, at very low cost by improving its agility of the manufacturing firm. A task of several highly developed technologies in Agile Manufacturing atmosphere has been examined through a few researchers. A number of them comprise computeraided design, CIM, computer-aided manufacturing, IT, computer-aided process planning (CAPP). A small number of papers coverage the researchers investigative the integration of such highly developed technologies in Agile Manufacturing environment.

\subsection{Agile Manufacturing Conception and Enabling}

\section{Technologies}

Even though there are many definitions of Agile Manufacturing brought out as a result of the researchers, the most familiar definition is, Agile Manufacturing is the ability of a manufacturing association to manufacture a range of products contained by a short period of time also in a cost effectiveness approach. Agile Manufacturing is an idea to standardize general manufacturing data, CAD/ CAM structure, research data, and join together them into a network. a standardized research data base and a general manufacturing data base are very critical for agility and can 
considerably decrease planning period and the product design period.

\subsection{Characteristics of Agile Manufacturing}

There are many characteristics of agile manufacturing such as show in following:

- Rapid new product development,

- Short lead times, cycle times,

- Use of superior CAD/CAM,

- Modular design and technology,

- $\quad$ highly flexible machines and equipment,

- Short and fast order processing,

- Fast supplier deliveries,

- Very Short time to market,

- Short guide times and short cycle times,

- Highly flexible and responsive processes,

- Modular assembly,

- Use of Solids model.

\subsection{Mold Industry}

In recent machinery manufacturing industry, mold industry has developed into the beginning industry for national financial system. Several innovative product development and production relies deeply on mold manufacturing expertise, especially in the light industry, automotive industry, and aerospace and electronics industries. The capability of mold manufacturing and stage of consequent technique has turn out to be a significant pointer of a nation's level of mechanical manufacturing technique. It straight affects several sectors of the nation's economy. Mold CAM/ CAD is developed from the origin brought concerning by the self-governing development of mold CAM and mold CAD. It is a novel jump in the wide-ranging application of mold manufacturing and computer technology.

The fast development of CAD/CAM technology and the further development of software and hardware level provided well-built technical support for mold industry and brought a jump on the quality of production level, endeavor product design and manufacturing. It has become the best option for a modern enterprise networking, integration and information.

\subsection{Mold CAD/CAM Design Flow}

By means of the rapid development of manufacturing technology and computer technology there are growing concerns on how to shorten machining production period and mold design time and to enhance manufacturing quality. Mold technology is also migrating regularly from manual design, relying on manual knowledge and ordinary machine processing skill to mold computer-aided design, aided engineering and aided manufacturing technology. The US has pioneered implementing computer technology on mold industry, realizing mold $\mathrm{CAD} / \mathrm{CAE} / \mathrm{CAM}$ incorporated system and achieving purposes of enhancing mold manufacture quality, boosting production period and design effectiveness.

\section{CONCLUSIONS}

This paper concluded the results of a study relating to advanced $\mathrm{CAD} / \mathrm{CAM}$ technologies in respect to product development and manufacture. This paper presented the present methodologies are being used and the future oriented methodologies will be preferred. CAD/CAM users as well as designers have been asked to rate several smart CAD/CAM technologies in respect to product development and manufacture. Furthermore, problems in reverence to the consciousness of product variant design have been discussed. The Constant development of product design and manufacturing increasingly inflict impacts upon smart $\mathrm{CAD} / \mathrm{CAM}$ technologies, proposing greater requirements for the research on and growth of CAD/CAM.

\section{REFERENCES}

[1] Paul S. Goodman, Terri L. Griffith, "A process approach to the implementation of new technology", Journal of Engineering and Technology Management, Volume 8, Issues 3-4, December 1991, Pages 261-285.

[2] Suk-Hwan Suh, Sung-Kee Noh, Yong-Jong Choi, “A PC-based retrofitting toward CAD/CAM/CNC integration", Computers \& Industrial Engineering, Volume 28, Issue 1, January 1995, Pages 133-146.

[3] Bjørn Moseng, Bjarte Haaøy, "Nes Integration of $\mathrm{CAD} / \mathrm{CAM}$ as seen from the production planners' point of view", Computers in Industry, Volume 5, Issue 4, December 1984, Pages 341-350.

[4] Guido Gürtler, "CAD Standard parts file - A DIN project in the standards committee on tabular layouts for article characteristics", Computer Standards \& Interfaces, Volume 6, Issue 4, 1987, Pages 473-481.

[5] Jakob Vlietstra, "Integration aspects in CAD and CAM", Computers in Industry, Volume 5, Issue 4, December 1984, Pages 295-296.

[6] D.A. Linkens, "CAD for control systems-a review of PC software", Computer-Aided Design, Volume 20, Issue 9, November 1988, Pages 564-565.

[7] Yoshihiro Ochiai, Tsuyoshi Sekiya, "Generation of free-form surface in CAD for dies", Advances in Engineering Software, Volume 22, Issue 2, 1995, Pages 113-118.

[8] Lex Lennings, "CAD/CAM integration in practice: Two cases of computer aided toolmaking", Computers in Industry, Volume 18, Issue 2, 1992, Pages 127-134.

[9] Ziga Turk, "Object-oriented modelling and integrated CAD", Automation in Construction, Volume 1, Issue 4, March 1993, Pages 323-337.

[10] Emad S. Abouel Nasr, Ali K. Kamrani, "A new methodology for extracting manufacturing features from CAD system", Computers \& Industrial Engineering, Volume 51, Issue 3, November 2006, Pages 389-415. 


\section{BIOGRAPHIE:}

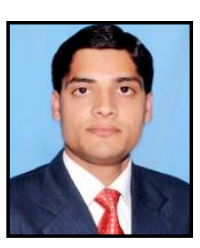

Pawan Sharma has completed his B.Tech (2011) in Mechanical Engineering \& M.Tech (2014) in Machine Design from RTU, Kota, India. He has published 28 research papers in the refereed International journals and conferences. His area of research includes CAD/CAM, FEA/FEM, Composite Materials, CFD and Vibration Analysis. 